\title{
Correlations between Homoeostatic Reserve and Mortality in Cancer: A Literature Review
}

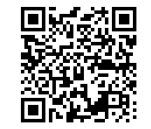

\author{
Sundardlas Dharmadas Annamalay* \\ Natural Therapies Research Centre, Singapore
}

Submission: October 31, 2017; Published: December 08, 2017

*Corresponding author: Sundardas Dharmadas Annamalay, Natural Therapies Research Center, Singapore, Email: annamalay@me.com

\begin{abstract}
This paper reviews the literature regarding the correlations between homoeostatic reserves and mortality for cancer. We will review the literature about the use of bio-impedance assessment (BIA) and heart rate variability (HRV) to assess homoeostatic reserves. We know that in the different stages of cancer the functional reserves change significantly. During the treatment and after the treatment of cancer the level of the homoeostatic reserve is a measure of morbidity and mortality. One way of measuring the functional reserves of the body is by using the bio-impedance assessment (BIA) and heart rate variability (HRV) assessment. Both the bio-impedance assessment and heart rate variability assessment are independent markers for homoeostatic reserves. For BIA the key marker appears to be the phase angle (PhA). For HRV the key marker appears to be the balance of the autonomic nervous system (ANS)
\end{abstract}

Keywords: Cancer; Heart rate variability assessment; Bio-impedance assessment; PhA; ANS

Abbreviations: BIA: Bio-Impedance Assessment; HRV: Heart Rate Variability; PhA: Phase Angle; ANS: Autonomic Nervous System ; AD: Autonomic Dysfunction

\section{Introduction}

\section{What is homoeostatic reserve?}

Homeostatic reserve is defined as the redundancy of physiologic functions present in human systems that is used to overcome acute and chronic health insults. The frailty phenotype [1] can be used as a marker indicating a critical threshold in decline of homeostatic reserve. Decline in the homoeostatic reserve has been hypothesized to be a contributing factor to progression of chronic disease states, development and worsening of geriatric syndromes, and decline in ability to perform activities of daily living [1,2]. Bioelectrical impedance analysis (BIA) is a simple, inexpensive, quick and non-invasive technique for measuring body composition and cell membrane function. The phase angle ( $\mathrm{PhA}$ ) in BIA provides a marker of the cell membrane function. Heart Rate Variability refers to the variation between the normal heart rate and a given mean value. Heart Rate Variability Assessment (HRV) can also be used to assess variation between the normal heart rate and a given mean value and autonomic dysfunction (AD).

As homoeostatic reserve declines, the individual in concern becomes increasingly unable to perform simple everyday duties, maintain appropriate blood pressure or balance, maintain healthy immunity to disease, modulate weight and so on [1]. This decline can be measured in many ways. Some of them include assessing the cell membrane function and autonomic dysfunction (AD). As such the state of the homeostatic reserve becomes one way of assessing the progression of physiological function in the case of cancer. Obviously as homoeostatic reserve declines it indicates that the organism's capacity to overcome the health insults due to cancer is reduced. When a critical threshold is reached, this decline becomes irreversible.

The phase angle (PhA) in BIA provides a marker of the cell membrane function. As the $\mathrm{PhA}$ declines, homoeostatic reserves can be said to be declining as well. For a long time, researchers have known that autonomic dysfunction (AD) causes death from heart disease and HRV analysis, which provides information about the autonomic nervous system (ANS) in various ailments [3-9]. HRV methods possess the ability to show the amount of dysfunction in ANS, brought about by disorders such as cancer. As the degree of $\mathrm{AD}$ increases homoeostatic reserves can be said to be declining as well. The focus is on two modes of monitoring the status: BIA and HRV

A. Variables involved in and those used to measure the BIA and HRV 
B. The impact of other variables like stress and disease on BIA and HRV as well as the relationship between these diseases and the changes in BIA and HRV

C. The use of BIA and HRV in the management of stress and cancer as well as the impact of different attempts at modulation.

\section{Methods and Materials}

A literature search was conducted using Pub Med, Medline and other databases for literature on the related topics to March 2016. The heading used was Bio-impedance and Cancer, Heart Rate Variability and Cancer. The search was limited to studies in the English language. It focused on clinical studies, clinical trials and reviews. Abstracts were screened and articles individually selected based on quality and focus of the study

\section{Introduction to BIA}

Bioelectrical impedance analysis (BIA) is a simple, inexpensive, quick and non-invasive technique for measuring body composition. "Impedance" is a physical variable describing the resistance characteristics of an electrical circuit in the presence of an alternating current between electrodes located in a circumference surrounding the studied object. Thus, it reflects global opposition to the passage of current [10].

Using bioelectrical impedance analysis as a diagnostic tool to examine the electrical characteristics of tissues provides information on a non-invasive and continuous basis, at the patient bedside without need for radiological investigations. Mathematically, the bioelectrical impedance is represented as a complex number comprising a real component (resistance) and an imaginary dimension (reactance) [3]. The electrical impedance $(\mathrm{Z})$ consists of two components, resistance $(\mathrm{R})$ and reactance (Xc). Resistance is a measure of total body water and reactance a measure of body cell mass (BCM). From the determined impedance a number of BIA parameters can be estimated [11].

Body Cell Mass (BCM), consists of all cells that have an effect on metabolism (\% BCM in FFM), extra cellular mass (ECM), extracellular water/fluid (ECW/ECF), fat-free mass (FFM), fat mass (FM), total body water (TBW) [12-15]. The impedance unit is the ohm $(\Omega)$, when this variable is applied to biological tissue we speak of "bio-impedance" [10]. In this context, it is very important to note that the biological tissues have complex electrical impedance. And that is dependent on the frequency of the electrical applied field and tissue cellular structure. Therefore, the electrical impedance of tissue is a function of its structure and it can be used to differentiate normal and cancerous tissues [16-18] in a variety of organs. Bio-impedance analysis could apply easily and routinely in the arm, trunk, and leg and from wrist to ankle.

One of the most important applications of the BIA is its use as a prognostic tool for overall survival, particularly for patients with severe cancers. In this concern, the phase angle (PhA), [19-22] is one of the most important indicators for predicting life quality and overall survival, particularly for cancer patients. Since, the phase angle provides a marker of cell membrane function, R0 and Ro have been used to predict clinical outcome. (R0 is the resistive part at zero frequency $(\Omega), \mathrm{R} \infty$ is the resistive part at infinite frequencies).

Physically, using of BIA method for characterizing different tissues is to fit data by the Cole equation models, which describe the behavior of permittivity and conductivity as a function of frequency. The commonly used circuit represents biological tissues activities, in which, the $\mathrm{R}$ of extracellular fluid is arranged in parallel to the second arm of the circuit "which consists of capacitance" and $\mathrm{R}$ of intracellular fluid in series. Resistive part (R) and capacitance can all be measured over a range of frequencies (most single frequency BIA analyzers operate at 50$\mathrm{kHz}$ ). At zero (or low) frequency, the current does not penetrate the cell membrane, which acts as an "insulator", and therefore the current passes through the extracellular fluid, which is responsible for the measured $\mathrm{R}$ of the body $\mathrm{R} 0$. At infinite frequency (or very high frequency) the capacitor behaves as a perfect (or near perfect) capacitor, and therefore the total body $\mathrm{R}$ $(\mathrm{R} \infty)$ reflects the combined of both intracellular and extracellular fluid. The impedance version is the Cole equation:

$$
\begin{aligned}
& Z(\omega)=R \infty+R 0-R \infty \\
& 1+(j \omega t) \alpha
\end{aligned}
$$

Where, $\mathrm{Z}(\omega)$ is the complex impedance in ohm $(\Omega)$, R0 is the resistive part at zero frequency $(\Omega), \mathrm{R} \infty$ is the resistive part at infinite frequencies $(\Omega), \mathrm{t}$ is a time constant, e.g., the mean relaxation time in a distribution of time constants, and $\alpha(\mathrm{p} / 2)$ is the constant phase angle, $\omega$ is the frequency (in $\mathrm{rad} \mathrm{s-1)}$ ), the constant1- $\alpha$ may also be viewed as describing the width of the distribution of time constants.

\section{Tissue identification and monitoring}

Any changes in tissue physiology should produce changes in the tissue electrical properties [23]. Based on this phenomenon, BIA analysis has been widely used to identify or monitor the presence of various illnesses or conditions such as body fluid shift, blood flow, cardiac output, and muscular dystrophy [2437]. Different tissues exhibit different electrical properties, in addition, tissue electrical properties change with respect to tissue status evolution. Thus it is easy to conceive that bioimpedance method can be applied to identify and monitor tissues. The bio-impedance method can be adopted for characterizing different tissues $[25,26]$. For instance, the lung tissues show a 5-fold greater electrical current resistance than the rest of the intrathoracic soft tissues [10]. During the cyclic breathing process, the impedance of the pulmonary tissues changes $5 \%$ in the context of calm breathing, and up to $300 \%$ when inhaling from residual volume to total lung capacity [38]. One of the most 
attractive applications of bio-impedance characterization is cancer detection $[29,34,39]$.

Hence, there are vast majority physiological differences in tumor tissues, thus BIA is efficiently applicable method for monitoring and distinguish normal healthy and tumor tissues. For instance tumors have much higher water content in their cells rather normal cells because of cellular necrosis and fenestrated vascularization and that will reflects on the tissue conductivity [16]. The cancerous tissues exhibit sharply different bioelectrical properties as compared with the normal tissues. The higher conductivity of tumors could lead to their selective targeting by radio frequency hyperthermia treatment [35]. In early stages of tumor a disturbance in the cellular water/electrolyte content, cell membrane permeability, and orientation/packing density of cells will occur. These changes and abnormalities will reflect on tissue impedance, which could be detected by using bioimpedance.

\section{Applications of Bia In health care, Medical diagnosis and quality of life}

Obesity is a common nutritional problem in both developed and developing countries. In a cross-sectional study, the prevalence of being overweight and obese using both bioelectrical impedance analysis (BIA) and body mass index (BMI) has been investigated. A close correlation for BMI and obesity has been confirmed [40]. A variety of BIA studies have been done in evaluating body composition including FFM, BF and BCM in multiple population samples [41-47].

On the other hand, in a prospective study the usefulness of bio-impedance measurement have been investigated for predicting the treatment outcome in breast cancer related lymphedema (BCRL) patients [32,46]. In this study, the ratio of extracellular fluid (ECF) volume has been investigated by using bioelectrical impedance spectroscopy (BIS), and single frequency bio-impedance analysis (SFBIA) at a $5 \mathrm{kHz}$ frequency before treatment[18,30,48-54].

They also investigated whether there is correlation between ECF ratio and SFBIA ratio with the change of arm circumference. The study concluded that ECF volume measurements and SFBIA before treatment are useful tools for predicting the outcome of patients with lymphedema $[49,50,54]$. Additionally, ECF volume measure can be used as a screening tool for predicting treatment outcome of BCRL patients [32]. There are lots of studies involved phase angle as a reliable predictive factor for quality of life and overall survival, particularly for cancer patients [55-58].

\section{Physiological parameters affecting bioelectrical impedance assessment accuracy}

Although the fact that an increased conductivity may be used to identify the presence of tumors [59,60], there are lots of limitations for BIA metric analysis due to the complication and variation in the biological system [61]. Their important review by author Damijan et al. [16] discussed efficiently lots of problems of biological concern.
Relative to water, fat is a much poorer conductor of electricity, thus the changes in body fat and water balance will reflect on tissue impedance. Cell and tissue death also cause many irreversible changes including viscosity of the extra/ intracellular fluids [62]. And promote changes in the mobility and distribution of ions which have the ability to transport the current. In the living physiological system, if the blood flow is interrupted, metabolism could continue in an anaerobic manner. That in turn, leads to an increase in the level of the extracellular fluid due to the osmotic pressure. Therefore, BIA when applied in such conditions, there is a false increase in the tissue impedance. Even, the brief decrease in the blood flow has an impact and could change tissue resistivity.

The respective figures are not absolute and can vary according to the conditions of the environment or medium (eg. temperature). A temperature increase is associated with a decrease in impedance [10], due to the prominent increase in ions mobility [63-65] that "transport the current", and decrease viscosity of the extracellular fluid. A general increase of about $2 \%$ occurs in the conductivity of tissue [33] in the frequency range below $1 \mathrm{GHz}$, up to a temperature of about $40^{\circ} \mathrm{C}$. Above that point, the cell membrane begins to deteriorate and allows the cytosol to leak into the extracellular space. Nevertheless, the rapid increase of conductivity with temperature was suggested to be used to monitor the progress of hyperthermia treatment [66].

\section{Conclusion [67]}

BIA works well in healthy subjects and chronic diseases with a validated BIA equation that is appropriate with regard to age, sex and race. The metric measurements includes: body mass index, fat-free mass, body fat, body cell mass, extracellular fluid, intracellular fluid, blood loss, and total body water [68]. Due to differences in growth velocity and puberty related changes Bioimpedance metric analysis interpretation in children is much more difficult. For instance, errors in estimation of fat mass using Bio-impedance analysis and Dual energy X-ray Absortiometry (DXA) can be very large, and the direction of error can differ between the sexes in children [40-42].

Furthermore, the Bio-impedance analysis device tested displayed poor individual accuracy for the estimation of body composition compared with a four compartment criterion method [43]. In this sense, it is very important to note that the use of segmental Bio-impedance analysis also requires further validation at increased temperature, edema and abnormal hydration. Thus, Bio-impedance analysis should be interpreted with caution until further validation has proven for Bioimpedance analysis algorithm to be accurate in such conditions.

The potential sources of errors for Bio-impedance analysis in some specific subjects may be due to increased bone mass of limbs and changes in skin thickness and hydration, which might influence the extension of the tissues electrical characteristics. The eight-electrode BIA model had also small, but systemic, 
errors in fat percentage and fat-free mass. These errors led to an overestimation of fat percentage in lean individuals among men and an underestimation of fat percentage among obese women. Therefore, the general use of eight electrode BIA model should be interpreted with caution, until the valid or recommend equations or the correction of these total errors is resolved.

Caution is recommended when using BIA as the body composition method for breast cancer survivors who have completed treatment but are still undergoing adjuvant hormonal therapy [62]. The use of more than one method should be used to derive more physiologically reliable information, which could be potentially useful for providing validation to avoid such errors [67]. Lastly, the clinical benefit of BIA can be further enhanced by combining it with bioelectrical impedance vector analysis (BIVA) [69]. However there is a simple way of ensuring errors are reduced. By ensuring that candidates do their baseline reading at particular centre and ensuring that they repeat their testing at the same centre at the same time, many of the errors will be reduced. The difference between the two readings will be an accurate indicator of the changes in the subject's status

\section{Introduction to HRV}

The origin of ECG is a special node which acts as a pacemaker for the heart. It is called the SA or Sinoatrial node, and assists in the acquisition of ECG when one attaches electrodes to specific points on the body, usually the right leg. The form and structure of the ECG as seen on a printed chart indicates whether an individual has a healthy heart or not. The first is the wave boundary and determination of the primary fiducial points, as shown by the onset and offset of the QRS complex as well as P and $\mathrm{T}$ waveforms. The baseline for the QRS-T is determined in an interval before the QRS onset. It is important to note that baseline wander, atrial fibrillation and a high or irregular heart rate can cause errors in ECG assessments.

Tests after tests show that the most suitable alternative for the development and assessment of ECG is the three channels CSE database, although it can only be used for assessments of one channel accuracy [70]. In order to accurately determine the ECG of an individual, several aspects are put into consideration. One of them is the HRV or Heart Rate Variability, which refers to the variation between the normal heart rate and a given mean value.

The autonomic nervous system innervates blood vessels, the airways, intestines and urogenital organs and is largely under involuntary control. It regulates and coordinates bodily functions by effecting secretory activity of glands and contraction and relaxation of smooth and cardiac muscle [71]. Autonomic neuropathy may be idiopathic or occur as a complication of other conditions or as result of drugs. It is recognised as a common complication in patients with diabetes mellitus; for many it remains subclinical, with only a minority experiencing symptoms such as postural hypotension, nausea, vomiting and early satiety related to gastroparesis, nocturnal diarrhea, bladder-emptying problems and male erectile dysfunction [72]. Autonomic dysfunction $(\mathrm{AD}$ ) has also been shown to be a negative prognostic indicator following acute myocardial infarction and stroke [73]. The underlying mechanism is thought to be an increased risk of cardiac arrhythmias as a result of decreased vagal tone [74]. Although the autonomic nervous system innervates all organs, due to the serious implications of cardiovascular autonomic dysfunction, investigation of autonomic function involving the cardiovascular system has become most established [75].

The heart rate may vary but may result from diabetes complications, fetal distress in a pregnant mother and congestive heart failure. One thing worth noting is that HRV is useful in predicting myocardial infarction. A reduced HRV is symptomatic of this condition which if left untreated is usually fatal. As said before, Heart Rate Variability is affected by Sympathetic and Parasympathetic system disorders, but those of the peripheral nervous and the central nervous systems also play a major role [76].

\section{Methods}

HRV analysis methods: The first thing to note is that HRV methods for analysis of heart rhythms, do not generally involve opening up the body and physically examining the heart. Usually, doctors employ three different methods namely, the Non Linear, time domain, and frequency domain methods. Even with these methods, one ought to consider various factors such as the individual in question's health status, respiration, gender and age. Other parameters that generally influenced HRV tests were abnormalities in the Sympathetic nervous System (SNS) and Parasympathetic nervous system (PNS).

Short term power spectra analyses produce peaks or clusters of data points mostly within three main regions [72]:

A. High Frequency (HF) from $0.15 \mathrm{~Hz}$ to $0.40 \mathrm{~Hz}$ reflects the activity of the parasympathetic system and the vagal nerve.

B. Low Frequency (LF) from $0.04 \mathrm{~Hz}$ to $0.15 \mathrm{~Hz}$ reflects sympathetic activity.

Very Low Frequency (VLF) from $0.003 \mathrm{~Hz}$ to $0.04 \mathrm{~Hz}$ reflects a host of factors, including not only the sympathetic nervous system, but also input from chemoreceptors, thermoreceptors, the reninangiotens in system and others. According to most research journals, the most frequently used technique for HRV is the linear technique, specifically Spectral Analysis. In this method, spectral power in a high frequency band is employed to reflect respiratory sinus arrhythmias while at the same time, a low frequency reflects baro-receptors control. Very low frequency power on the other hand shows the vascular and thermo-regulatory functions of the heart [73].

\section{HRV analysis of diseases}

Heart rate variation techniques and indexes have proved crucial in treating not just cardiovascular system diseases, but unrelated conditions such as stroke, Alzheimer, renal failure, leukemia, epilepsy, chronic migraines, and obstructive sleep apnea. Most doctors tend to agree that all biological systems, 
even the healthy ones tend to show haphazard dynamics while biological systems suffering from disease show reduced levels of dynamics. Since all organs depend on the flow of blood from the heart, any cardiovascular abnormalities will affect all other organs and affect the heart rate activity.

That said, autonomic dysfunction is a key characteristic of heart and diseases such as sepsis, brain trauma, multiple organ failure, and myocardial infarction. Other conditions that show high HRV indices include Congestive Heart Block (CHB), Left Branch Bundle Block (LBBB), Sick Sinus Syndrome (SSS) and Premature Ventricular Contraction (PVC). As said before, Heart Rate Variability is affected by Sympathetic and Parasympathetic system disorders, but those of the peripheral nervous and the central nervous systems also play a major role $[74,75]$.

\section{HRV analysis of cancer}

Autonomic dysfunction has been described in patients with advanced cancer, in whom a high prevalence of AD is identified [68,76-79]. Postulated causes include decreased physical activity, treatment with vinca alkaloids or other medications, or paraneoplastic processes [80-87]. The precise contribution of AD to clinical findings and prognosis in advanced cancer is unclear. Only one study has demonstrated a relationship between AD and symptoms in patients with advanced cancer; Bruera et al. [80] found that patients with advanced breast cancer in whom all tests of cardiovascular autonomic function were abnormal were more likely to report symptoms of postural hypotension and chronic unexplained nausea [88-94]. More recent research on AD in advanced cancer has focused on its prognostic significance; a small number of studies have identified a relationship between $\mathrm{AD}$ and shorter survival in advanced cancer [95-100].

\section{Conclusion}

ANS deregulation causes death from heart disease and HRV analysis, which provides information about the ANS in various ailments. ANS dysregulation is also observed in cancer. There appears to be a relationship between $\mathrm{AD}$ and survival rates in cancer. The small number of studies using the latter methodology means caution should be employed before any generalizations being made regarding the superiority of one technique over the other.

\section{Overall Summary}

Both BIA and HRV provide a quick, low cost means to monitor the homeostatic reserves of a patient with cancer. They also provide means of assessing the efficacy of a treatment protocol as well as prognosis of survival rates. The author has used the above two assessment methods for the management of chronic conditions and cancer for almost fifteen years. The author has found these two approaches very complementary and useful in the prognosis and management of chronic conditions and cancer. By ensuring that candidates do their baseline reading at particular centre and ensuring that they repeat their testing at the same centre, many of the errors in BIA and HRV readings will be reduced. The difference between the two readings will be an accurate indicator of the changes in the subject's status. The small numbers of studies however suggest that further research should be undertaken before coming to any definitive conclusion.

\section{References}

1. Fried LP, Tangen CM, Walston J, Newman AB, Hirsch C, et al. (2001) Frailty in older adults: Evidence for a phenotype. J Gerontol A Biol Sci Med Scin 56(3): 146-156.

2. Rowe JW, Kahn RL (1987) Human aging: Usual and successful. Science 237(4811): 143-149.

3. Acharya R, Kumar A, Bhat PS, Lim CM, lyengar SS, et al. (2004) Classification of cardiac abnormalities using heart rate signals. Med Bio Eng Comp 42(3): 288-293.

4. Hales S Statistical Essays: Containing Haemastaticks. Innys, Manby, Woodward, London, UK, p. 1733.

5. Gang Y, Malik M (2003) Heart rate variability analysis in general medicine. Indian Pacing Electrophysiol J 3(1): 34-40.

6. Chua CK, Chandran V, Acharya RU, Min LC (2009) Cardiac health diagnosis using Higher order spectra and support vector machine. Open Med Inform J 3: 1-8.

7. Schroeder R, Voss A, Vallverdu M, Cygankiewicz I, Vazquez R, et al. (2008) Linear and Non Linear heart Rate variability Risk stratification in Heart failure patients. Computers in cardiology 35: 957-959.

8. Gostovic MJ, Krastic G, (2003) Non linear analysis of Heart rate variability in Patients with Coronary Heart Disease. Chicago Computers in cardiology 29: 673-675.

9. Denton TA, Diamond GA, Helfant RH, Khan S, Karagueuzian H (1990) Fascinating rhythm: a primer on chaos theory and its application to cardiology. Am Heart J 120(6): 1419-1440.

10. Riera J, Riu PJ, Casan P, Masclans JR (2011) Electrical impedance tomography in acute lung injury. Med Intensiva 35(8): 509-517.

11. Asadullina NR, Usacheva AM, Gudkov SV (2012) Protection of mice against X-ray injuries by the post-irradiation administration of inosine-5 monophosphate. J Radiat Res 53: 211-216.

12. Liston A, Bayford R, Holder D (2012) A cable theory based biophysical model of resistance change in crab peripheral nerve and human cerebral cortex during neuronal de polarisation: implications for electrical impedance tomography of fast neural activity in the brain. Med Biol Eng Comput 50(5): 425-437.

13. Chatziioannidis I, Samaras T, Nikolaidis N (2011) Electrical Impedance Tomography: a new study method for neonatal Respiratory Distress Syndrome? Hippokratia 15(3): 211-215.

14. Martins TC, Camargo ED, Lima RG, Amato MP, Tsuzuki M (2012) Image reconstruction using interval simulated annealing in electrical impedance tomography. IEEE Trans Biomed Eng 59(7): 1861-1870.

15. Raneta O, Ondruš D, Bella V (2012) Utilization of electrical impedance tomography in breast cancer diagnosis. Klin Onkol 25(1): 36-41.

16. Damijan M, Natasa P, Francis XH (2006) Electric properties of biological tissues. Wiley Encyclopedia of Biomedical Engineering.

17. Kim KH, Yoo HY, Joo KM, Jung Y, Jin J, et al. (2011) Time-course analysis of DNA damage response-related genes after in vitro radiation in $\mathrm{H} 460$ and H1229 lung cancer cell lines. Exp Mol Med 43(7): 419-426.

18. Czerniec SA, Ward LC, Refshauge KM, Beith J, Lee MJ, et al. (2010) Assessment of breast cancer-related arm lymphedema-comparison of physical measurement methods and self-report. Cancer Invest 28(1): 54-62.

19. Foster KR, Schwan HP (1989) Dielectric properties of tissues and biological materials: a critical review. Crit Rev Biomed Eng 17(1): 25104. 
20. Crawford GB, Robinson JA, Hunt RW, Piller NB, Esterman A (2009) Estimating survival in patients with cancer receiving palliative care is analysis of body composition using bio-impedance helpful? J Palliat Med 12(11): 1009-1014.

21. Sánchez Lara K, Turcott JG, Juárez E, Guevara P, Núñez-Valencia C, et al. (2012) Association of nutrition parameters including bioelectrical impedanceand systemic inflammatory response with quality of life and prognosis in patients with advanced non-small-cell lung cancer: a prospective study. Nutr Cancer 64(4): 526-534.

22. Gupta D, Lammersfeld CA, Vashi PG, King J, Dahlk SL, et al. (2009) Bio electrical impedance phase angle in clinical practice: implications for prognosis in stageIIIB and IV non-small cell lung cancer. BMC Cancer 9: 37.

23. Blad B, Wendel P, Jönsson M, Lindström K (1999) An electrical impedance index to distinguish between normal and cancerous tissues. J Med Eng Technol 23(2): 57-62.

24. San-Frutos L, Engels V, Zapardiel I, Perez-Medina T, Almagro-Martinez J, et al. (2011) Hemodynamic changes during pregnancy and postpartum: a prospective study using thoracic electrical bio-impedance. J Matern Fetal Neonatal Med 24(11): 1333-1340.

25. Kalvoy H, Martinsen OG, Grimnes S (2008) Determination of tissue type surrounding a needle tip by electrical bio-impedance. Conf Proc IEEE Eng Med Biol Soc, pp. 2285-2286.

26. Rundle A, Richards C, Neugut AI (2009) Body composition, abdominal fat distribution, and prostate-specific antigen test results. Cancer Epidemiol Biomarkers Prev 18(1): 331-336.

27. Noshiro M, Morimoto T, Nagao H, Matsuda H (1993) Electrical impedance in the lower limbs of patients with Duchenne muscular dystrophy: a preliminary study. Med Biol Eng Comput 31(2): 97-102.

28. Harris ND, Suggett AJ, Barber DC, Brown BH (1987) Applications of applied potential tomography (APT) in respiratory medicine. Clin Phys Physiol Meas 8: 155-165.

29. do Amaral CE, Lopes HS, Arruda LV, Hara MS, Gonçalves AJ, et al. (2011) Design of a complex bio-impedance spectrometer using DFT and undersampling for neural networks diagnostics. Med Eng Phys 33(3): 356-361.

30. Ward LC, Dylke E, Czerniec S, Isenring E, Kilbreath SL (2011) Confirmation of the reference impedance ratios used for assessment of breast cancer-related lymphedema by bioelectrical impedance spectroscopy. Lymphat Res Biol 9(1): 47-51.

31. Cagini L, Capozzi R, Tassi V, Savignani C, Quintaliani G, et al. (2011) Fluid and electrolyte balance after major thoracic surgery by bio-impedance and endocrine evaluation. Eur J Cardio thorac Surg 40(2): 71-76.

32. Crawford GB, Robinson JA, Hunt RW, Piller NB, Esterman A (2009) Estimating survival in patients with cancer receiving palliative care is analysis of body composition using bio-impedance helpful? J Palliat Med 12(11): 1009-1014.

33. Halaska M, Strnad P, Chod J, Malá I, Nováková M, et al. (2007) [Detection of postoperative lymphoedema in patients with breast cancer]. Ceska Gynekologie 72(4): 299-304.

34. Gonzalez-Correa CA, Brown BH, Smallwood RH, Stephenson TJ, StoddardCJ, et al. (2003) Low frequency electrical bio-impedance for the detection of inflammation and dysplasia in Barrett's oesophagus. Physiol Meas 24(2): 291296.

35. Joines WT, Zhang Y, Li C, Jirtle RL (1994) The measured electrical properties of normal and malignant human tissues from 50 to 900 MHz. Med Phys 21(4): 547-550.

36. Heydari ST, Ayatollahi SM, Zare N (2011) Diagnostic Value of Bioelectrical Impedance Analysis versus Body Mass Index for Detection of Obesity among Students. Asian J Sports Med 2(2): 68-74.
37. Kim L, Jeon JY, Sung IY, Jeong SY, Do JH, et al. (2011) Prediction of treatment outcome with bio-impedance measurements in breast cancer related lymphedema patients. Ann Rehabil Med 35(5): 687-693.

38. Harris ND, Suggett AJ, Barber DC, Brown BH (1987) Applications of applied potential tomography (APT) in respiratory medicine. Clin Phys Physiol Meas 8: 155-165.

39. Burden ST, Hill J, Shaffer JL, Todd C (2010) Nutritional status of pre operative colorectal cancer patients. J Hum Nutr Diet 23(4): 402-407.

40. Cole TJ, Bellizzi MC, Flegal KM, Dietz WH (2000) Establishing a standard definition for child overweight and obesity worldwide: international survey. BMJ 320: 1240-1243.

41. Haroun D, Croker H, Viner RM, Williams JE, Darch TS, et al. (2009) Validation of BIA in obese children and adolescents and re-evaluation in a longitudinal study. Obesity (Silver Spring) 17(12): 2245-2250.

42. Reilly JJ, Gerasimidis K, Paparacleous N, Sherriff A, Carmichael A, et al. (2010) Validation of dual-energy x-ray absorptiometry and foot-foot impedance against deuterium dilution measures of fatness in children. Int J Pediatr Obes 5(1): 111-115.

43. LaForgia J, Gunn S, Withers RT (2008) Body composition: validity of segmental bioelectrical impedance analysis. Asia Pac J Clin Nutr 17(4): 586-591.

44. Vilaça KH, Paula FJ, Ferriolli E, Lima NK, Marchini JS, et al. (2011) Body composition assessment of undernourished older subjects by dualenergy x-ray absorptiometry and bioelectric impedance analysis. J Nutr Health Aging 15(6): 439-443.

45. Lubans DR, Morgan P, Callister R, Plotnikoff RC, Eather N, et al. (2011) Tes-tretest reliability of a battery of field-based health-related fitness measures for adolescents. J Sports Sci 29: 685-693.

46. Desport JC, Preux PM, Bouteloup-Demange C, Clavelou P, Beaufrère B, et al. (2003) Validation of bioelectrical impedance analysis in patients with amyotrophic lateral sclerosis. Am J Clin Nutr 77(5): 1179-1185.

47. Wells JC, Fuller NJ, Wright A, Fewtrell MS, Cole TJ (2003) Evaluation of air-displacement plethysmography in children aged 5-7 years using a three component model of body composition. Br J Nutr 90(3): 699-707.

48. Badalato GM, Wosnitzer MS, Truesdale MD, Sandri M, Ko WJ, et al. (2011) Evaluation of preoperative bio-impedance spectroscopy quantification of body composition on predicting postoperative outcomes following robotic assisted radical prostatectomy (RARP). Can J Urol 18(6): 6031-6036.

49. Fu MR, Guth AA, Cleland CM, Lima ED, Kayal M, et al. (2011) The effects of symptomatic seroma on lymph edema symptoms following breast cancer treatment. Lymphology 44(3): 134-143.

50. Liu LN, Miaskowski C, Wang JS, Chen SC, Chen ML (2010) Accuracy of body mass index to determine obesity in women with breast cancer: an observational study of Taiwanese sample. Int J Nurs Stud 47(8): 9941000 .

51. Halpern-Silveira D, Susin LR, Borges LR, Paiva SI, Assunção MC, et al. (2010) Body weight and fat-free mass changes in a cohort of patients receiving chemotherapy. Support Care Cancer 18(5): 617-625.

52. Wallström P, Bjartell A, Gullberg B, Olsson H, Wirfält E (2009) A prospective Swedish study on body size, body composition, diabetes, and prostate cancer risk. Br J Cancer 100(11): 1799-1805.

53. Isenring E, Colombo M, Cross G, Kellett E, Swaney L (2009) Estimation of total body water from bioelectrical impedance spectroscopy in oncology outpatients receiving radiotherapy and agreement with three prediction equations. J Hum Nutr Diet 22(1): 50-54.

54. Wu GH, Cao DX, Wei J, Quan YJ, Wu ZH (2008) Assessment of energy expenditure and body composition in cancer patients. Zhonghua Wai Ke Za Zhi 46(24): 1906-1909. 
55. Vicini F, Shah C, Lyden M, Whitworth P (2012) Bioelectrical impedancefor detecting and monitoring patients for the development of upper limblymph edema in the clinic. Clin Breast Cancer 12(2): 133137.

56. Wang T, Wang K, Yao Q Chen JH, Ling R, et al. (2010) Prospective study on combination of electrical impedance scanning and ultrasound in estimating riskof development of breast cancer in young women. Cancer Invest 28(3): 295-303.

57. Sánchez-LK, Turcott JG, Juárez E, Guevara P, Núñez-Valencia C, et al (2012) Association of nutrition parameters including bioelectrical impedanceand systemic inflammatory response with quality of life and prognosis inpatients with advanced non-small-cell lung cancer: a prospective study. Nutr Cancer 64(4): 526-534.

58. Gupta D, Lammersfeld CA, Vashi PG, King J, Dahlk SL, et al. (2009) Bio electrical impedance phase angle in clinical practice: implications for prognosis in stageIIIB and IV non-small cell lung cancer. BMC Cancer 9: 37.

59. Haemmerich D, Wood BJ (2006) Hepatic radiofrequency ablation at low frequencies preferentially heats tumour tissue. Int J Hyperthermia 22(7): $563-574$

60. Haemmerich D, Staelin ST, Tsai JZ, Tungjitkusolmun S, Mahvi DM, et al. (2003) In vivo electrical conductivity of hepatic tumours. Physiol Meas 24(2): 251-260.

61. Blad B, Wendel P, Jönsson M, Lindström K (1999) An electrical impedance index to distinguish between normal and cancerous tissues. J Med Eng Technol 23(2): 57-62.

62. Badalato GM, Wosnitzer MS, Truesdale MD, Sandri M, Ko WJ, et al. (2011) Evaluation of preoperative bio-impedance spectroscopy quantification of body composition on predicting postoperative outcomes following robotic assisted radical prostatectomy (RARP). Can J Urol 18(6): 6031-6036.

63. Cole KS (1949) Some physical aspects of bioelectric phenomena. Proc Natl Acad Sci 35(10): 558-566.

64. Nopp P, Rapp E, Pfützner H, Nakesch H, Ruhsam C (1993) Dielectric properties of lung tissue as a function of air content. Phys Med Biol 38(6): 699-716

65. Kim Y, Webster JG, Tompkins WJ (1983) Electrical impedance imaging of thethorax. J Microw Power 18(3): 245-257.

66. Sun SS, Chumlea WC, Heymsfield SB, Lukaski HC, Schoeller D, et al (2003) Development of bioelectrical impedance analysis prediction equations for body composition with the use of a multi component model for use in epidemiologic surveys. Am J Clin Nutr 77(2): 331-340.

67. Tuorkey MJ (2012) Bioelectrical Impedance as a Diagnostic Factor in the Clinical Practice and Prognostic Factor for Survival in Cancer Patients: Prediction, Accuracy and Reliability. J Bio sens Bioelectron 3: 121.

68. Walsh D, Nelson K(2002) Autonomic nervous system dysfunction in advanced cancer. Supportive Care in Cancer 10: 523-528.

69. Walter-Kroker A, Kroker A, Mattiucci-Guehlke M, Glaab T (2011) A practical guide to bioelectrical impedance analysis using the example of chronic obstructive pulmonary disease. Nutr J 10: 35.

70. Acharya R, Kumar A, Bhat PS, Lim CM, lyengar SS, et al. (2004) Classification of cardiac abnormalities using heart rate signals. Med Bio Eng Comp 42(3): 288-293.

71. Gabella G (2001) Autonomic Nervous System. ELS John Wiley \& Sons Ltd.

72. Kumar P (2005) Clarke ML: Clinical Medicine. Elsevier Saunders, London, p. 6.
73. McLaren A, Kerr S, Allen L, Steen N, Ballard C, et al. (2005) Autonomic function is impaired in elderly stroke survivors. Stroke 36(5): 10261030 .

74. Fei L, Statters DJ, Hnatkova K, Poloniecki J, Malik M, et al. (1994) Change of autonomic influence on the heart immediately before the onset of spontaneous idiopathic ventricular tachycardia. J Am Coll Cardiol 24 (6): 1515-1522.

75. Vinik AI, Maser RE, Mitchell BD, Freeman R (2003) Diabetic Autonomic Neuropathy. Diabetes Care 26 (5): 1553-1579.

76. Electrophysiology Journal 3(1) 34-40.

77. Bruera E, Chadwick S, Fox R, Hanson J, MacDonald N (1986) Study of cardiovascular autonomic insufficiency in advanced cancer patients. Cancer Treatment Reports 70 (12): 1383-1387.

78. Gould G, Ashworth M, Lewis G (1986) Are cardiovascular reflexes more commonly impaired in Patients with bronchial carcinoma? Thorax 41(5): 372-375

79. Strasser F, Palmer JL, Schover LR, Yusuf SW, Pisters K, et al. (2006) The impact of hypogonadism and autonomic dysfunction on fatigue, emotional function, and sexual desire in male patients with advanced cancer: a pilot study. Cancer 107 (12): 2949-2957.

80. Roca E, Bruera E, Politi PM, Barugel M, Cedaro L, et al. (1985) Vinca alkaloid-induced cardiovascular autonomic neuropathy. Cancer Treatment Reports 69(2):149-151.

81. Verstappen CCP, Heimans JJ, Hoekman K, Postma TJ (2003) Neurotoxic complications of chemotherapy in patients with cancer: clinical signs and optimal management. Drugs 63(15): 1549-1563.

82. Kim D, Choi YS, Kim JA, Kim SH, Kim DG (2007) Heart rate variability for prediction of life span in hospice cancer patients. 10th Congress of the European Association for Palliative Care. Budapest, Hungary.

83. Fadul N, Strasser F, Palmer JL, Yusuf SW, Guo Y, et al. (2010) The association between autonomic dysfunction and survival in male patients with advanced cancer: a preliminary report. J Pain Symptom Manage 39 (2): 283-290.

84. Chiang JK, Koo M, Kuo TBJ, Fu CH (2010) Association between cardiovascular autonomic functions and time to death in patients with terminal hepato cellular carcinoma. J Pain Symptom Manage 39(4): 673-679.

85. Haemmerich D, Ozkan R, Tungjitkusolmun S, Tsai JZ, Mahvi DM, et al. (2002) Changes in electrical resistivity of swine liver after occlusion and post mortem. Med Biol Eng Comput 40(1): 29-33.

86. Kim H, Kim CH, Kim DW, Park M, Park HS, et al. (2011) External cross validation of bioelectrical impedance analysis for the assessment of body composition in Korean adults. Nutr Res Pract 5(3): 246-252.

87. Hoyle GE, Chua M, Soiza RL (2011) Volaemic assessment of the elderly hypo natraemic patient: reliability of clinical assessment and validation of bioelectrical impedance analysis. QJM 104(1): 35-39.

88. Bussolotto M, Ceccon A, Sergi G, Giantin V, Benincà P, et al. (1999) Assessment of body composition in elderly: accuracy of bioelectrical impedance analysis. Gerontology 45(1): 39-43.

89. Nagai M, Komiya H, Mori Y, Ohta T, Kasahara Y, et al. (2010) Estimating visceral fat area by multi frequency bioelectrical impedance. Diabetes Care 33(5): 1077-1079.

90. Medoua GN, Ndzana Abomo AC, Essa'a VI, Sobgui CM, Messomo MT, et al. (2008) Validity of impedance-based equations for the prediction of total body water as measured by deuterium dilution in Cameroonian HIV-infected patients treated with antiretroviral treatment. Clin Nutr 27(6): 881-888. 
91. Paton NI, Elia M, Jennings G, Ward LC, Griffin GE (1998) Bioelectrical impedance analysis in human immunodeficiency virus-infected patients: comparison of single frequency with multi frequency, spectroscopy, and other novel approaches. Nutrition 14(9): 658-666.

92. Sluys TE, van der Ende ME, Swart GR, van den Berg JW, Wilson JH (1993) Body composition in patients with acquired immunodeficiency syndrome: avalidation study of bioelectric impedance analysis. JPEN J Parenter Enteral Nutr 17(5): 404-406.

93. Kushner RF, Schoeller DA (1986) Estimation of total body water by bio electrical impedance analysis. Am J Clin Nutr 44(3): 417-424.

94. Schoeller DA, Luke A (2000) Bioelectrical impedance analysis prediction equations differ between African Americans and Caucasians, but it is not clear why. Ann N Y Academy of Sciences 904: 225-226.

95. Kotler DP, Burastero S, Wang J, Pierson RN (1996) Prediction of body cell mass, fat-free mass, and total body water with bioelectrical impedance analysis: effects of race, sex, and disease. Am J Clin Nutr 64(3): 489-497.
96. Nordenson A, Grönberg AM, Hulthén L, Larsson S, Slinde F (2010) A validated disease specific prediction equation for resting metabolic rate in underweight patients with COPD. Int J Chron Obstruct Pulmon Dis 5 : 271-276.

97. Harris JA, Benedict FG (1918) A Biometric Study of Human Basal Metabolism. Proc Natl Acad Sci 4(12): 370-373.

98. Jiménez A, Omaña W, Flores L, Coves MJ, Bellido D, et al. (2012) Prediction of whole-body and segmental body composition by bioelectrical impedance inmorbidly obese subjects. Obes Surg 22(4): 587-593.

99. Zhao Z, Möller K, Steinmann D, Frerichs I, Guttmann J (2009) Evaluation of an electrical impedance tomography-based Global In homogeneity Index for pulmonary ventilation distribution. Intensive Care Med 35(11): 1900-1906.

100. Norman K, Stobäus N, Zocher D, Bosy-Westphal A, Szramek A et al. (2010) Cut off percentiles of bioelectrical phase angle predict functionality, quality of life, and mortality in patients with cancer. Am J Clin Nutr 92(3): 612-619.

\section{Your next submission with Juniper Publishers will reach you the below assets}

- Quality Editorial service

- Swift Peer Review

- Reprints availability

- E-prints Service

- Manuscript Podcast for convenient understanding

- Global attainment for your research

- Manuscript accessibility in different formats

( Pdf, E-pub, Full Text, Audio)

- Unceasing customer service

Track the below URL for one-step submission https://juniperpublishers.com/online-submission.php 